\title{
Histerektomi Materyallerinde Histopatolojik Tanıların Değerlendirilmesi
}

\author{
The Evaluation Of Histopathological Diagnosis In Hysterectomy Materials
}

\author{
Çiğdem Kunt İşgüder'1, Hatice Yılmaz Doğru' ${ }^{1}$, Asker Zeki Özsoy', Bülent Çakmak', İlhan Bahri \\ Delibaş ${ }^{1}$, Akgül Arıcı $^{2}$, Fazlı Demirtürk ${ }^{1}$
}

1 Gaziosmanpaşa Üniversitesi Tıp Fakültesi Kadın Hastalıkları ve Doğum A.D. TOKAT

2 Gaziosmanpaşa Üniversitesi Tıp Fakültesi Patoloji A.D., TOKAT.

\section{ÖZET}

Amaç: Bu çalışmanın amacı; benign endikasyonlarla yapılan histerektomilerin preoperatif klinik endikasyonlarının ve postoperatif histopatolojik tanılarının değerlendirilmesidir.

Gereç ve Yöntem: Mart 2013-Mayıs 2015 tarihleri arasında Gaziosmanpaşa Üniversitesi Tıp Fakültesi Kadın Hastalıkları ve Doğum Kliniği'nde benign endikasyonlarla histerektomi uygulanan 170 hastanın klinik özellikleri ve postoperatif histopatolojik tanı raporları retrospektif olarak değerlendirildi.

Bulgular: Hastaların yaş ortalaması $50.48 \pm 7.50$ (min:38, max:74) idi. En sık histerektomi endikasyonu 77 olgu (\%45.3) ile leiomyoma idi. Daha sonra sırası ile disfonksiyonel uterin kanama 50 (\%29.49) ve endometrial hiperplazi 22 (\%12.9) olarak tespit edildi. Diğer klinik endikasyonlar uterus prolapsus 17 (\%10), kronik pelvik ağrı 2 (\%1.2) ve adenomyozis 2 (\%1.2) idi. Histerektomi materyallerinin histopatolojik raporlarının değerlendirilmesi sonucunda, en yaygın patoloji leiomyoma 87olguda (\%51.2), takiben adenomyozis 35 olguda (\% 20.5) ve endometrial hiperplazi 31 (18.3) saptandı. Endometrial polip 10 olguda (\%5.9) ve 7 olguda (\%4.1) ise atrofik endometrium mevcuttu. 44 histerektomi materyalinde kombine patoloji tanımlandı. \%50 oranında leiomyoma ve endometrial hiperplazi en yaygın kombibasyon olarak tespit edildi. Ayrıca histerektomi materyallerinin serviks incelemelerinde \%64.7 'sinde kronik servisit olduğu gözlendi.

Sonuç: 4. ve 5. dekatta açıklanamayan menometroraji, sekonder dismenore ve kronik pelvik ağrı ile başvuran hastaların tanısında ve tedavileri planlanırken mutlaka adenomyozis akla gelmelidir. Leiomyama ve endometrial hiperplazilerin yüksek oranda birlikteliğinden dolayı leiomyoma tanısıyla histerektomi planlanan olgularda menometroraji de mevcut ise endometrial örnekleme yapılmasının gerekli olduğu görülmektedir. Ioji

Anahtar Kelime: Histerektomi, histerektomi endikasyonları, pato-

Corresponding Author: Çiğdem Kunt İşgüder

Address: GOP Üniv. Tıp Fak. Kadın Hast. ve Doğum A.D. TOKAT

E-mail: cidos_55@hotmail.com

\section{ABSTRACT}

Aim: The aim of this study is to assess the preoperative clinic indications and postoperative histopathological diagnosis of hysterectomies with benign indications.

Materilas and Methods: Clinical features and reports of postoperative histopathological diagnosis of 170 patients, whose underwent hysterectomy with benign indications in Gaziosmanpasa University Medical Faculty Department of Obstetrics and Gynecology, were retrospectively evaluated.

Results: The mean age of the patients was $50.48 \pm 7.50$ (min:38, max:74). Leiomyoma with 77 case (\%45.3) was the most hysterectomy indicated disease. Thereafter, dysfunctional uterine bleeding in 50 (\%29.49), and endometrial hyperplasia 22 (\%12.9) were detected. The other clinical indications were uterine prolapse in 17 patients (\%10), chronic pelvic pain in 2 (\%1.2) and adenomyosis in 2 (\%1.2). The results of histopathological reports belong to hysterectomy materials indicated that leiomyoma was the most common pathological finding with 87 cases (\%51.2), subsequently adenomyosis in 35 cases (\% 20.5) and endometrial hyperplasia in 31 (18.3) was detected. Endometrial polyp was found in 10 cases (\%5.9) and atrophic endometrium in 7 cases (\%4.1). Combined pathology was defined in 44 hysteterctomy materials. Leiomyoma and endometrial hyperplasia were detected as the most common combination with a ratio of $\% 50$. In addition, chronic cervicitis was seen in \%64.7 of cervical examinations of hysterectomy materials.

Conclusion: Adenomyosis should be kept in mind while planning the diagnosis and treatment of patients whose admitted with compliants of menometrorrhagia, seconder dysmenorrhea and chronic pelvic pain in 4th and 5th decade. Endometrial sampling caused by the coexistence of leiomyoma and endometrial hyperplasia must be necessary in hysterectomy planned cases for leiomyoma those already have menometrorrhagia.

Keywords: hysterectomy, hysterectomy indications, pathology. 


\section{Giriş}

Disfonksiyonel uterin kanama (DUK), leiomyoma, adenomyozis, endometriozis, uterovaginal prolapsus, kronik pelvik ağrı, pelvik inflamatuar hastalık, jinekolojik kanserler, obstetrik komplikasyonlar ve gestasyonel trofoblastik hastalıkların tedavisinde uygulanan histerektomi, sezaryandan sonra yapılan en sık jinekolojik cerrahi prosedür (1-3) olup ilk kez 1884 yılında Clay tarafından total abdominal histerektomi ile bilateral salpingoooferektomi operasyonu olarak yapılmıștır. Her yaştan 1000 kadın için histerektomi hızı 6,1 ile 8,6 arasında değişmektedir. Histerektomilerin 2/3'ü 40-55 yaş arası, 1/3'ü 65 yaş civarındaki kadınlara uygulanmaktadır (4). Birleşik Krallık'ta kadınların yaşamlarının herhangi bir döneminde histerektomi operasyonu geçirme oranı \%20'dir. (5). Tüm dünyada uterin leiomyomlar histerektominin en sık endikasyonudur (6). Kadınların \%20-30'u DUK'tan etkilenir ve bu problemi olan kadınların\%60 । histerektomiye gider. Coğrafik dağılım, hasta ve hekim ile ilişkili faktörlere bağlı olarak histerektomi oranları değişiklik gösterir (7).

Bu çalışmada kliniğimizde benign endikasyonlarla yapılan histerektomilerin preoperatif klinik endikasyonlarının ve postoperatif histopatolojik tanılarının değerlendirilmesi amaçlandı.

\section{MATERYAL VE METOD}

Mart 2013-Mayıs 2015 tarihleri arasında Gaziosmanpaşa Üniversitesi Tıp Fakültesi Kadın Hastalıkları ve Doğum Kliniği'nde benign endikasyonlarla total abdominal histerektomi yapılan 170 hastanın kayıtları ve histerektomi materyalinin histopatolojik tanı raporları gözden geçirildi. Operasyon öncesi rutin jinekolojik muayenesi ve transvaginal ultrasonografisi yapılan olguların hepsinin preoperatif pap smear ve fraksiyone küretaj testlerinin sonuçları mevcuttu. Endometrial poliplerin tedavisi için öncelikle dilatasyon ve küretaj veya histereskopik rezeksiyon yapıldı. Atipinin olmadığı endometrial hiperplazili olgulara öncelikle medikal tedavi uygulandı, tedaviye dirençli olgularda histerektomi planlandı. Verilerin İstatistiksel analizinde SPSS 18.0 programı kullanıldı.

\section{BULGULAR}

Çalışmaya toplam 170 hasta dahil edilmiştir. Hastaların yaş ortalaması 50.48 \pm 7.50 (min:38, max:74) idi. En sık histerektomi endikasyonu 77 olgu (\%45.3) ile myoma uteri idi. Daha sonra sırası ile disfonksiyonel uterin kanama 50 (\%29.49) ve endometrial hiperplazi 22 (\%12.9) olarak tespit edildi. Diğer klinik endikasyonlar uterus prolapsus 17 (\%10), kronik pelvik ağrı 2 (\%1.2) ve adenomyozis 2 (\%1.2) idi (Tablo 1 ).

\begin{tabular}{|l|c|c|}
\hline \multicolumn{3}{|l|}{ Tablo 1. 170 Histerektomi olgusunda klinik endikasyonlar (\%) } \\
\hline Klinik Endikasyon & Sayı (n) & Oran (\%) \\
\hline Myoma uteri & 77 & 45.3 \\
\hline Disfonksiyonel uterin kanama & 50 & 29.4 \\
\hline Endometrial hiperplazi & 22 & 12.9 \\
\hline Uteus prolapsus & 17 & 10.0 \\
\hline Kronik pelvik ağrı & 2 & 1.2 \\
\hline Adenomyozis & 2 & 1.2 \\
\hline
\end{tabular}

Histerektomi materyallerinin histopatolojik raporları değerlendirildiğinde, en sık leiomyoma 87olguda (\%51.2), takiben adenomyozis 35 olguda (\% 20.5) ve endometrial hiperplazi 31 (18.3) saptandı. 10 olguda (\%10) endometrial polip, 7 olguda (\%4.1) ise atrofik endometrium mevcuttu (Tablo 2).

Tablo 2. 170 Histerektomi materyalinde tespit edilen patolojilerin tipleri ve oranları

\begin{tabular}{|l|c|c|}
\hline Histopatolojik Tanı & Sayı (n) & Oran (\%) \\
\hline Leiomyoma & 87 & 51.2 \\
\hline Adenomyozis & 35 & 20.5 \\
\hline Endometrial hiperplazi & 31 & 18.3 \\
\hline Endometrial polip & 10 & 5.9 \\
\hline Atrofik endometrium & 7 & 4.1 \\
\hline
\end{tabular}

Çalışmamızda 44 olguda birden fazla patoloji tespit edildi. En sık birlikte görülen patolojiler myoma uteri ve endometrial hiperplazi 22 (\%50), daha az sıklıkta sırası ile myoma uteri ile adenomyozis 8 (\%18.2), myoma uteri ile endometrial polip 7(\%15.9), adenomyozis ile endometrial polip 3 (\%6.8) tespit edildi.

Çalışmamızda endometrial hiperplazilerin dağılımı Tablo 3'te gösterildi. En sık basit atipisiz 
endometrial hiperplazi 8 (\%47.1) daha az sıklıkta kompleks atipili hiperplazi 6 (\%35.3), 2 vakada (\%11.8) basit atipili hiperplazi ve 1 vakada da kompleks atipisiz endometrial hiperplazi tespit edildi.

\begin{tabular}{|l|c|c|}
\hline \multicolumn{3}{|l|}{$\begin{array}{l}\text { Tablo 3. Histopatolojik olarak endometrial hiperplazi tespit } \\
\text { edilen } 17 \text { olgunun tip dağılımı }\end{array}$} \\
\hline Histopatolojik Tanı & Sayı (n) & Oran(\%) \\
\hline Basit atipisiz endometrial hiperplazi & 8 & 47.1 \\
\hline Kompleks atipili hiperplazi & 6 & 35.3 \\
\hline Basit atipili hiperplazi & 2 & 11.8 \\
\hline $\begin{array}{l}\text { Kompleks atipisiz endometrial } \\
\text { hiperplazi }\end{array}$ & 1 & 5.8 \\
\hline
\end{tabular}

Leiomyoma için ortalama yaş $48.5( \pm 6.4)$ iken adenomyozis için $48.3( \pm 3.0)$, endometrial hiperplazi için $50.8( \pm 8.0)$, endometrial polip için $56.6( \pm 6.8)$ ve atrofik endometrium için 59.86 $( \pm 10.0)$ idi.

Kompleks atipili endometrial hiperplazi tanısıyla opere edilen 56 yaşındaki bir hastada endometrioid tip endometrial adenokarsinoma tespit edildi.

Histerektomi materyallerinin serviks incelemelerinde \%64.7'sinde kronik servisit olduğu gözlendi.

\section{TARTIŞMA}

Histerektomi kadın doğum pratiğinde en sık uygulanan cerrahi prosedürlerin başında gelmektedir. Endikasyon alanı geniştir; leiomyoma, adenomyozis, endometriozis, uterovaginal prolapsus, kronik pelvik ağrı, pelvik inflamatuar hastalık, jinekolojik kanserler ve obstetrik komplikasyonlar ve gestasyonel trofoblastik hastalıkların tedavisinde uygulanmaktadır (5). Histerektomilerin büyük çoğunluğu 40-55 yaşları arasında yapılmaktadır (8). Çalışmamızda da histerektomi uygulanan olguların yaş ortalaması $50.48 \pm 7.5$ olup literatür ile benzerlik göstermektedir.

Leiomyom uterusun en sık rastlanan benign tümörüdür. Üreme çağındaki kadınların \%20-30 'unda görülür. Bütün premenapozal kadınların \% 20-77 'sinde oluşur (9). Leiomyomlar en sık histerektomi nedeni olup semptomları nedeniyle yılda yaklaşık 140.000 histerektomi ve 20.000 myomektomi yapılmaktadır (10). Vessey ve arkadaşları 1885 histerektomi olgusunu değerlendirmiş ve en sık histerektomi endikasyonunu sırasıyla leiomyom \%38.5, disfonksiyonel uterin kanama (\%35.3), uterin prolapsus (\%6.5) ve genital maligniteler (\%5.6) olarak bildirmişlerdir (7). Dinçgöz ve arkadaşları 949 vakalık serilerinde \%32.2 ile leiomyomanın en sık histerektomi nedeni olduğunu bulmuşlardır (11). Bizim çalışmamızda da histerektomi endikasyonları içerisinde leiomyoma ilk sırada olup 77 (\%45.3) olguya ve ikinci sırada disfonksiyonel uterin kanama nedeniyle 50 (\%29.4) hastaya histerektomi uygulanmıştır. Çalışmamız benign endikasyonlarla histerektomi yapılan olguları içerdiği için maligniteye rastlanılmamıştır. Ojeda ve arkadaşları 621 olguyu değerlendirdikleri çalışmalarında \%44.76 leiomyoma, \%22.33 endometrial hiperplazi, \%14 adenomyozis, \%12.23 malign hastalık ve \%6.44 endometriozis tespit etmişlerdir (12). İsaoğlu ve arkadaşları 258 olgu içeren çalışmalarının patoloji sonuçlarında \%32.17 leiomyoma, \%30.23 adenomyozis ve \%29,84 endometrial hiperplazi bildirmişlerdir (13) Bizim çalışmamızın histopatoloji sonuçlarının değerlendirilmesinde en sık leiomyoma \%51.2, sonra sırasıyla adenomyozis $\% 20.5$, endometrial hiperplazi $\% 18.3$ ve endometrial polip \%5.9 oranında tespit edilmiştir.

Adenomyozis, endometrial gland ve stromanın derin myometrial doku içerisinde yer alması olarak tanımlanmakta olup etyolojisi ve patolojik mekanizması tam olarak bilinmemektedir. Ancak progesteron tarafından karşılanmamış uzamış östrojen aktivitesinin etyolojide rol oynadığı düşünülmektedir $(14,15)$. Adenomyozisde uterus diffuz olarak büyür ve sıklıkla uterin leiomyomlar adenomyozise eşlik eder (16). Zaman zaman daha genç yaştaki kadınlarda görülse de semptomatik kadınların yaş ortalaması genellikle 40 yaş ve üstüdür (17). Adenomyozis semptomlarının leiomyom, endometriozis ve endometrial poliplerde de görülebilmesi ve birden fazla patolojinin birlikte olabilmesi nedeniyle klinik olarak adenomyozis tanısı \%2.6 ile \%26 arasında değişmekte olup gerçek tanısı ancak patoloji ile konulur. Benign jinekolojik nedenlerle yapılan histerektomi materyallerinde adenomyozis sıklığı \%20-30 olarak bildirilmektedir (18). İsaoğlu ve arkadaş- 
ları, 258 histerektomi materyalini histopatolojik olarak inceledikleri çalışmalarında adenomyozis sıklığını \%30.23 olarak belirtmişler (13), biz de çalışmamızda histerektomi materyallerinde adenomyozis görülme sıklığını literatürdeki oranlara benzer \%20.5 olarak bulduk. Ayrıca 8 adenomyozisli vakada eşlik eden leiomyoma tespit edilmiştir.

Endometrial hiperplazi, progesteron ve progestagenlerle karşılanmamış endojen ve eksojen östrojenik stimülasyona bağlı olarak endometrial gland ve stromada oluşan morfolojik ve biolojik değişiklikler olarak tanımlanmaktadır. Anormal uterin kanama ile kendini gösteren endometrial hiperplazi bütün yaş gruplarındaki kadınları etkileyen genel jinekolojik bir durum (19) olup endometriumun endometrioid adenokarsinomu için prekürsördür. Endometrial hiperplazi endometrial glandların yapısına ve sitolojik atipinin varlığına göre basit ve kompleks, atipili ve atipisiz endometrial hiperplazi şeklinde sınıflandırılmaktadır. Basit ve kompleks atipisiz endometrial hiperplazilerin kansere ilerleme oranları sırasıyla $\% 1$ ve $\% 3$ olup, basit atipili ve kompleks atipili hiperplazilerde bu oran sırasıyla \%8 ve \%29 'dur. Ortalama kansere ilerleme süresi atipisiz hiperplazilerde yaklaşık 10 yıl iken, atipili hiperplazilerde 4.1 yıldır $(19,20)$. Çalışmamızda endometrial hiperplazi oranı \%18.3 idi. Atipisiz endometrial hiperplazilerde öncelikle medikal tedavi uygulanmış, tedaviye dirençli olgularda olgunun klinik durumuna göre histerektomi yapılmıştır.

Endometrial polipler (EP), sıklıkla kanama düzensizliklerine yol açan, reprodüktif ve postmenapozal kadınlar arasında sık görülen bir problemdir. Genel populasyonda EP'lerin sıklığının yaklaşık olarak \%15-\%25 olduğu tahmin edilmekte, pre ve postmenapozal kadınlar arasında anormal uterin kanamanın en sık görülen nedenidir (21-23). Bizim çalışmamızda endometrial polip görülme oranı \%5.9 idi. Histopatolojik olarak EP tespit oranının düşük olmasının nedeni, endometrial poliplerin tedavisinde öncelikle di- latasyon-küretaj (D\&C) ve histereskopik rezeksiyon yapılmasıdır.

Talukder ve arkadaşları 328 olguda serviksi histopatolojik olarak değerlendirmişler ve \%87.8 oranında kronik servisit tespit edildiğini bildirmişlerdir (24). Bizim çalışmamızda da kronik servisit oranı \%64.7 idi.

Histerektomi materyallerinin histopatolojik incelenmesi sırasında birden fazla patolojinin birlikteliğine rastlanılmaktadır. Shegill ve arkadaşları 100 histerektomi materyalininin patolojilerini gözden geçirdikleri çalışmalarında; 38 olguda leiomyoma ile birlikte adenomyozis, 25 olguda leiomyoma ve sadece 3 olguda adenomyozis bildirmişlerdir (25). Bizim çalışmamızda ise 22 olguda (\%50) leiomyoma ve endometrial hiperplazi, 8 olguda (\%18.2) leiomyoma ile adenomyozis, 7 olguda (\%15.9) leiomyoma ile endometrial polip ve 3 olguda (\%6.8) adenomyozis ile endometrial polip tespit edildi.

Sonuç olarak çalışmamızda, benign nedenlerle histerektomi yapılan olgularda klinik ön tanılar arasında adenomyozis oranı çok düşük (\%1.2) olmasına rağmen histerektomi materyallerinde çok daha yüksek oranlarda (\%24.1) tespit edildi. Bu nedenle özellikle 4. ve 5. dekatta açıklanamayan menometroraji, sekonder dismenore ve kronik pelvik ağrı ile başvuran hastalarda mutlaka adenomyozis akla gelmelidir.

Histerektomi materyallerinin histopatolojik değerlendirilmesi sonucunda endometrial hiperplazi görülme oranının, preoperatif düşünülen değerden daha fazla olduğu tespit edildi. Leiomyama ve endometrial hiperplazilerin yüksek oranda birlikteliğinden dolayı leimyoma tanısıyla histerektomi planlanan olgularda menometroraji de mevcut ise endometyrial örneklemenin gerekli olduğu görülmektedir.

Çalışma grubumuzda kronik servisit oranı \%64.7 oranında olup oldukça yüksek oranda tespit edilmiştir. Bu da kadınların jinekolojik muayene açısında yetersiz değerlendirildiğinin bir göstergesi olabilir. 


\section{KAYNAKLAR}

1. Pokras R. Hysterectomy, past, present and future. Stat Bull Metrop Insur Co 1989; 70(4)12-21.

2. Benrubi GI. History of hysterectomy. J Fla Med Assoc 1988; 75: 533-8

3. Davies A, Magos A. Indications and alternatives to hysterectomy. Bailliere's Clin Obstet and Gynaecol 1997; 11(1): 61- 75.

4. Wilcox LS, Koonin LM, Pokras R, Strauss LT, Xia Z, Peterson HB. Hysterectomy in the United States, 19881990. Obstet Gynecol 1994;83(4):549-55.

5. Coulter A, Bradlow J, Agass M, Martin-Bates C, Tulloch A. Outcomes of referrals to gynaecology outpatient clinics for menstrual problems: an audit of general practice records. Br J Obstet Gynaecol 1991; 98(8): 789-96.

6. Rock JA, Jones HW III, Histerektomi, In: Te Linde's Operatif Jinekoloji 9. Basım, Çeviri Editörü: Erol Tavmergen, İzmir Güven Kitabevi 2005: Bölüm 31, Sayfa 731 755.

7. Vessey MP, Villard-Mackintosh L, McPherson K, Coulter A, Yeats $D$. The epidemiology of hysterectomy: find-ings in a large cohort study. Br J Obstet Gynecol 1992; 99(5): 402-7.

8. Sandberg SI, Barnes BA, Weinstein MC, Braun P. Elective hysterectomy. Benefits, risks, and costs. Medical Care. 1985;23(9):1067-85.

9. Eisinger SH1, Meldrum S, Fiscella K, le Roux HD, Guzick DS. Low-dose mifepristone for uterine leiomyomata. Obstet Gynecol. 2003 Feb;101(2):243-50.

10. Lepine LA, Hillis SD, Marchbanks PA, et al. Hysterectomy surveillance- United States 1980-1997. MMWR 1997; 46(4): 1-15.

11. Dinçgez B, Coşkun EI, Ayanoğlu YT. Kliniğimizde gerçekleştirilen histerektomi olgularının değerlendirilmesi. Şişli Etfal Hastanesi Tıp Bülteni 2011; 45(2): 35-8.

12. Ojeda VJ. The pathology of hysterectomy specimens. $Z$ Med J 1979; 89(631): 169-71.

13. İsaoğlu Ü, Yılmaz M, Delibaş I, et al. The Evaluation of Histopathologic Diagnosis in Specimens of Hysterectomy Abant Med J 2013; 2(2):91-94
14. Ferenczy A. Pathophysiology of adenomyosis. Hum Reprod Update 1998; 4(4): 312-322.

15. Leyendecker G, Wildt L, Mall G. The pathophysiology of endometriosis and adenomyosis: tissue injury and repair. Arch Gynecol Obstet 2009; 280(4): 529-38.

16. Arif A, Jamal S, Mubarik A, Zubair A, Ghori UK. Study of adenomyosis in different decades of life: An experience at army medical college, Rawalpindi-Pakistan. Pak J Pathol 2007; 18: 75-78.

17. Lee NC, Dicker RC, Rubin GL, Ory HW. Confirmation of the preoperative diagnoses for hysterectomy. Am J Obstet Gynecol 1984; 150(3): 283-7.

18. Kunz G, Beil D, Huppert P, Noe M, Kissler S, Leyen-decker $\mathrm{G}$. Adenomyosis in endometriosis prevalence and impact on fertility. Evidence from magnetic resonance imaging. Hum Reprod 2005; 20(8): 2309-16.

19. Kurman RJ, Kaminski PF, Norris HJ. The behavior of endometrial hyperplasia. A long term study of 'untreated' hyperplasia in 170 patients. Cancer 1985; 5682): 403-12.

20. Terakawa N, Kigawa J, Taketani Y,et al. The behavior of endometrial hyper-plasia: a prospective study. Endometrial Hyperplasia Study Group. J Obstet Gynaecol Res 1997; 23(3): 223-30

21. Sherman ME, Mazur MT, Kurman RJ. Benign diseases of the endometrium. In: Kurman RJ, editor. Blaunstein's pathology of the female genital tract. 5 . edition. New York: Springer, 2002; 421-466.

22. Perez-Medina T, Martinez O, Folgueira G, Bjo J. Which endometrial polyps should be resected? J Am Assoc Gynecol Laparosc 1999; 6(1): 71-74.

23. Reslova T, Tosner J, Resl M, Kugler R, Vavrova I. Endometrial polyps. A clinical study of 245 cases. Arch Gynecol Obstet 1999; 262(3-4): 133-9.

24. Talukder SI, Haque MA, Hug MH, Alam MO, Roushan A, Noor Z, Nahar K. Histopathological analysis of hysterec-tomy specimens. Mymensing Med J 2007; 16(1): 81-4.

25. Shegill SK, Shergill HK. Clinicopathological study of hysterectomies. J Indian Med Assoc 2002; 100(4): 238-9. 